Relations industrielles

Industrial Relations

\title{
Le service provincial de placement
}

Volume 1, numéro 2, octobre 1945

URI : https://id.erudit.org/iderudit/1023904ar

DOI : https://doi.org/10.7202/1023904ar

Aller au sommaire du numéro

Éditeur(s)

Département des relations industrielles de l’Université Laval

\section{ISSN}

0034-379X (imprimé)

1703-8138 (numérique)

Découvrir la revue

Citer cet article

(1945). Le service provincial de placement. Relations industrielles / Industrial Relations, 1(2), 7-7. https://doi.org/10.7202/1023904ar

Tous droits réservés @ Département des relations industrielles de l’Université Laval, 1945
Ce document est protégé par la loi sur le droit d'auteur. L’utilisation des services d'Érudit (y compris la reproduction) est assujettie à sa politique d'utilisation que vous pouvez consulter en ligne.

https://apropos.erudit.org/fr/usagers/politique-dutilisation/ 


\section{NÉCESSITÉ DES ASSOCIATIONS PATRONALES}

Nous assistons à une rapide expansion du syndicalisme au Canada. Ainsi, on estime que l'effectif des associations ouvrières a augmenté dans une proportion de plus de $85 \%$ depuis le début des hostilités. Parallèlement à ce développement du syndicalisme, la législation ouvrière a subi de profondes transformations, notamment par l'adoption du principe des négociations collectives obligatoires. Cependant, on semble croire, en certains milieux, que seuls les travailleurs bénéficient des lois favorables à l'organisation professionnelle.

Or, cela est inexaet. La législation du travail favorise aussi bien le droit d'association des employeurs que celui des travailleurs, tout cómme elle fait appel à la collaboration franche et loyale du Capital et du Travail. $\mathrm{Si}$, aujourd'hui, la classe ouvrière semble avoir atteint un degré de cohésion que ne possèdent pas les employeurs dans le domaine des relations industrielles, le blâme n'en peut être attribué qu'aux employeurs.

Il est vrai que les patrons ont leurs associations professionnelles. Mais on peut se demander si ces associations accordent aux problèmes des relations entre le Capital et le Travail un intérêt aussi prononcé que celui qu'elles apportent aux problèmes techniques, commerciaux et tarifaires. Combien d'employeurs s'imaginent pouvoir régler seuls leurs relations avec la classe ouvrière ! Il faut noter, toutefois, une grande amélioration de ce côté, depuis quelques années. Certaines associations patronales ont formé des comités spécialement chargés d'étudier les relations entre le Capital et le Travail. C'est une évolution que l'on doit souligner et encourager. Les employeurs ont alors l'occasion de se familiariser avec la législation ouvrière ; cela leur permet de déterminer exactement non seulenent leurs droits mais aussi leurs obligations. Lorsque vient le moment pour eux de rencontrer les syndicats et de négocier les conditions de travail, ils évitent plus facilement de commettre des erreurs qui peuvent être fatales à la stabilité et au progrès de leurs entreprises.

Les employeurs ne devraient donc pas hésiter à joindre les rangs d'une bonne association patronale. Plus le syndicalisme patronal se dóveloppera, plus il sera possible de donner un essor au régime de l'extension juridique des conditions de travail. Par là, nous aboutirons à une meilleure uniformisation des heures de travail et des salaires à l'intérieur de chaque industrie. Les employeurs, conscients de leurs responsabilités sociales, seront alors protégés contre une petite minorité peu soucieuse des intérêts de toute la collectivité.

Souhaitons, en conséquence, que les associations patronales connaissent un développement équivalent à celui des syndicats ouvriers.

Jean-Pierre Després.

\section{LE SERVICE PROVINCIAL DE PLACEMENT}

Les bureaux de placement de la province de Québec ont pour but d'enregistrer à la fois les offres d'emploi que leur adressent les employeurs et les noms des individus qui sollicitent du travail. Une première sélection professionnelle de la main-d'œuvre s'opère dans ces bureaux où l'employeur est presque toujours sûr de trouver du personnel qualifié et l'ouvrier, un travail convenant à ses dispositions et à ses goûts.

Les bureaux de placement constitủent un chaînon important du mécanisme complexe qui doit assurer l'embauchage intégral. Remarquons que Québec est la seule province du Dominion à maintenir des bureaux de placement distincts de ceux de la Commission d'assurance-chômage.

En vertu dêl'article 8 de la Loi concernant les bureaux de placement, le ministre du Travail peut permettre à certains organismes de maintenir des bureaux de placement privés. Les associations ouvrières, les sociétés de bienfaisance et certains gros employeurs se prévalent de ce privilège ; ils n'ont cependant pas le droit d'exiger de rémunération en retour de leurs services.
Les statistiques du bureau provincial de placement révèlent qu'au cours du mois de septembre 1945, 7,979 personnes ont sollicité du travail tandis que l'on a enregistré 7,916 offres d'emploi. Les placements se sont chiffrés à 7,559. Cependant, ces statistiques, considérées comme indice de l'embauchage général, sont relatives. Beaucoup de personnes enregistrées aux bureaux de placement provinciaux trouvent du travail chez des employeurs dont les noms ne figurent pas sur les listes des bureaux ou qui n'ont pas de service de placement officiel. D'autre part, des personnes, momentanément en chômage, trouvent de l'emploi sans l'intermédiaire des bureaux de placement provinciaux. L'indice le plus sûr de l'embauchage nous. est fourni par la Commission d'assurance-chômage où se font les demandes de prestations.

Les bureaux de placement du ministère du Travail sont ouverts au grand public. Il n'en coûte rien pour utiliser leurs services. Des bureaux provinciaux existent à Hull, La Tuque, Montréal, Québec, Trois-Rivières, Val d'Or, Chandler, Granby, Jonquière, Matane, Rouyn et Saint-Hyacinthe. 